provided that there is no special morbidity associated with its use. The experience of Sculco and Ranawat ${ }^{4}$ with spinal anaesthesia has been encouraging and this technique is now being used in Gartnavel. Our results so far indicate that when spinal anaesthesia is used the operative blood loss and the postoperative DVT rate are both reduced by about $50 \%$ compared with general anaesthesia.

JAMES R LOUDON J THORBURN

James GRaHam RAMSAY VALLANCE

Gartnavel General Hospital,
Glasgow

GERALD MCGARRITY

Victoria Infirmary,

Glasgow

1 Nicolaides, A N, and Irvine, D, in Thromboembolism: Aetiology, Advances in Prevention and Management, ed A N Nicolaides, p 193. Lancaster, MTP, 1975.
2 Eftekar, N S, et al, Clinical Orthopaedics, 1973, 95, 48.

3. Sagar, S, et al, Lancet, 1976, 1, 1151 .
Sculco, T P, and Ranawat, C, fournal of Bone and foint Surgery, 1975, 57A, 173.

SIR,-I wish to comment on the excellent paper on the failure of aspirin to prevent postoperative deep-vein thrombosis in patients undergoing total hip replacement (22 April, p 1031). Without faulting the conclusion of Mr J D Stamatakis and his colleagues that aspirin in a dose of $600 \mathrm{mg}$ twice daily is an ineffective prophylaxis against this complication, I think that there are other considerations to be borne in mind.

Aspirin inhibits haemostasis through two mechanisms. The most widely known mechanism is inhibition of platelet aggregation, ${ }^{1}$ and for this purpose $600 \mathrm{mg}$ twice daily is apparently adequate. However, and this is less well known but probably as important, aspirin interferes with the hepatic synthesis of vitamin-K-dependent clotting proteins, ${ }^{2}$ and does so in a manner quantitatively related to the plasma level attained and not necessarily to the dose administered to any given individual. $^{3}$ It therefore seems evident that optimum results will not be achieved by administration of a standard dose but are more likely to be attained by attention to the plasma level of aspirin in each individual.

J A MCSHERRY

Carruthers Clinic

1 Evans, G, et al, fournal of Experimental Medicine, 1968, 128, 877

Woodbury, $\mathrm{D} \dot{\mathrm{M}}$, in The Pharmacological Basis of Therapeutics, ed L S Goodman and A Gilman, edn, pp 314-328. New York, Macmillan, 1970.

and Clinical Medicine, 1946, 31, 428.

\section{Neoplasms of the lung}

SIR,-The otherwise excellent article by Dr E D Gilby (20 May, p 1331) repeats nevertheless what must surely be medicine's most shameful lie, that smoking is a habit. Essentially, smoking is a poisoning, a poisoning by nicotine, carbon monoxide, and tobacco tar. Almost all other chronic poisonings are accepted as diseases-poisoning by lead, asbestos, silica, thyrotoxicosis, and poisonings by many organisms and micro-organisms. Our sole raison d'être is to get rid of disease. Why have we failed so appallingly to get rid of this unpleasant, deadly, (psychologically) infectious, but wholly preventable and curable disease?
The reason, in my view, is moral-a lack of dedication to our job and of courage at all times to take an uncompromisingly antismoking stand.

LENNOX JOHNSTON

Lymington, Hants

Psychological and social effects of myocardial infarction on wives

SIR,-Certain aspects of the paper by $\mathrm{Dr}$ Richard Mayou and others (18 March, p 699) recounting psychosocial effects on wives of their husbands' heart attacks struck me as rather puzzling.

Firstly, the authors did not deem it requisite to supply comparative evidence from controls (other than the patients themselves, an obviously selected group). Thus, for instance, even when family crises are absent morbidity surveys of housewives generally reveal surprisingly high prevalences of definite psychiatric disturbance, ${ }^{1}$ especially in the lower socioeconomic classes (the authors fail to provide a social class breakdown of their findings, surely a variable worth mentioning in a psychosocial study). It would surely have been helpful if the authors had stated whether their morbidities exceed these. Certainly the fact that most $(83 \%)$ of the wives did not increase their own medical consultation rate belies the appreciable psychiatric morbidity the authors claim to have found. Moreover, can one really, as the authors purport to do, determine the specific effect of a wife on a patient's rehabilitation if one does not include infarcted bachelors?

Again, the incidence of moderate or severe mental disturbance at the initial interview $(38 \%)$ was significantly less than at two months (almost $60 \%$ ) as well as at one year $(58 \%)$. The authors omit to explain this rapid and sustained rise. It is surely surprising that there should be less psychological disturbance at the time of the trauma than a year later. By that time one would have expected the wives to have adjusted, at least to a degree. The authors themselves confirm that the infarction is at first overwhelmingly important but later is viewed in more perspective. How do they reconcile this with their results showing persistent disturbance?

It is curious too that approximately fourfifths of wives had nil or only mild mental symptoms at both two months and one year, whereas in the same table (table I) almost $60 \%$ of wives are said to have the same symptoms in either moderate or severe degree. The authors do not clarify this apparent discrepancy.

Mental state is reported as positively correlated with state of the marriage, marital change, and social activities. We are informed also that four-fifths of the marriages either improved or stayed the same, and there was a similar, actually $68-97 \%$, no change/improvement percentage in work, leisure, social contacts and chores scores. But, as we have seen, nearly $60 \%$ of the wives were still quite disturbed at one year. Their mental disturbance would therefore appear to be having little detrimental effect on either marriage or social activities and satisfaction. Indeed, the authors state that more marriages improved than deteriorated. This surely contradicts the main thesis of the paper.

Again, the authors state at one point (p 701, para 1) that $21 \%$ of the total group of wives were severely distressed, whereas their table I gives the figure as $28 \cdot 1 \%$. Another seeming contradiction is the reference in the summary to the comparability of the psychosocial disability of patients and their wives. For whereas two-thirds of patients had fewer leisure activities and $61 \%$ did fewer chores, we are also told (table II) that there was upward of $70 \%$ no change/improvement in wives' activities and satisfaction at one year. How can the authors reconcile these data? Finally, is there any precedent from other illnesses, based on good evidence, for the authors' assumption that counselling of wives improves their husbands' rehabilitation prospects? Surely a good wife will in any case give her husband the succour he needs; no amount of advice will really be likely to improve her performance.

Morpeth,

H G KINNELL

Northumberland

An Introduction to Medical Sociology, ed D Tuckett, 322. London, Tavistock Publ, 1976.

* * We sent a copy of this letter to Dr Mayou, whose reply is printed below.-ED, $B M \mathcal{F}$

SIR,-The compressions of editing and printing which meant that our results were somewhat less fully presented than in our original manuscript have I think misled Dr Kinnell. Perhaps I could first comment on the figures, taking his points in turn.

The wives were more disturbed at the time of hospital admission, but, as mentioned in the text, we used a different and briefer scale at this time and direct comparisons with mental state at later interviews were not possible. Table I gives examples of individual symptom ratings on a four-point scale, but the overall rating in the bottom line is a classification in three categories of an overall score obtained by summing ratings of six principal symptoms. The figures in the table are not therefore comparable in the way that Dr Kinnell assumes. Our later reference to $21 \%$ of the wives being severely distressed should refer to those wives who did not have a history of psychological symptoms.

While I appreciate that the conciseness of our report may have caused some puzzlement, I think your correspondent shows a somewhat captious scepticism and makes a number of unsupported assumptions:

(1) Control group-Dr Kinnell is wrong in believing that we were attempting to determine the specific effect of a wife on a patient's rehabilitation: the paper was presented as a description of the effect of illness on the wives. Of course it would be valuable to have a controlled study (what controls?), but at this stage of knowledge it appeared more appropriate to provide basic information and to introduce satisfactory quantitative measures, especially as the description of the consequences for wives was but a small part of a study principally concerned with the patients themselves.

(2) Correlation of outcome measures-The lack of association between some of the psychological and social measures cannot be taken as an indication of unreliability. It was in fact one of our principal findings that neither for patients nor for their wives can overall judgments of psychosocial adjustments be made. For each individual patient it is necessary to consider each aspect of social life (work, leisure, marriage, family) and mental state as well as compliance with advice and consultation. The relationship between these variables is extremely complex.

(3) Comparability of patients and wives-We do not suggest that outcomes for patients and wives 